$\underline{\xi}=-m$

\title{
Gastroprotective effect of ethylacetate fraction of the leaves of Hannoa klaineana on aspirin and histamine-induced gastric ulcer in rats
}

\author{
Ibrahim Abubakar'*, Hassan Muhammad Yankuzo², Yushau Shuaibu Baraya3, Muazu Abubakar Gusau ${ }^{1}$ \\ ${ }^{I}$ Department of Biochemistry, Faculty of Science, Usmanu Danfodiyo University Sokoto, Nigeria \\ ${ }^{2}$ Department of Medical Biochemistry, College of Health Sciences, Usmanu Danfodiyo University Sokoto, Nigeria \\ ${ }^{3}$ Department of Pathology, Faculty of Veterinary Medicine, Usmanu Danfodiyo University Sokoto, Nigeria \\ *Corresponding author E-mail:ibrahimabubakarsok@gmail.com
}

\begin{abstract}
Background: Peptic ulcer disease remains endemic in our society affecting about four million people every year worldwide. Hannoa klaineana is used traditionally in the treatment of various gastrointestinal diseases including ulcer.

Aim: This study aims at evaluating the gastroprotective effect of ethylacetate fraction of the leaves of Hannoa klaineana (Simaroubaceae).

Methods: The gastroprotective effect of ethylacetate fraction of the Hannoa klaineana (50, 100 and 200mg/kg b.wt) was evaluated using aspirin and histamine induced ulcer models.

Results: In aspirin-induced ulcer model, the ethylacetate fraction of the Hannoa klaineana demonstrated significant $(p<0.001)$ decreased in mean ulcer index with the maximum protective effect $(99.84 \%)$ at $200 \mathrm{mg} / \mathrm{kg}$ against the gastric damages. While histamine-induced ulcer model, the solvent fraction significantly $(p<0.001)$ decreased mean ulcer index with the protective effect up to $99.83 \%$ against the gastric lesions. In both models, a significant $(p<0.001)$ increased in $\mathrm{pH}$ value coupled with significant $(p<0.001)$ decreased in gastric volume, free and total acidity in rats pre-treated with varying doses of the ethylacetate fraction was found.

Conclusion: The mechanism of gastroprotective effects of ethylacetate fraction of the Hannoa klaineana could be attributed to its ability to stimulate prostaglandins secretion or possess prostaglandins like-substances or suppression of histamine-induced vasospastic effect and gastric secretion.
\end{abstract}

Keywords: Aspirin; Gastric acid; Hannoa klaineana; Histamine; Prostaglandin.

\section{Introduction}

Ulcer is a gasto-intestinal disease characterized by disruption of mucosal integrity of the stomach, duodenum or lower esophagos (Kumar et al., 2011). Every year, almost four million people are suffering by peptic ulcer disease (PUD) worldwide (Klein-Junior et al., 2010; Zelickson et al., 2011). Ulcers are classified base on their etiology into Type I and Type II ulcers. Type I ulcers occur as a result of impairment in mucosal protective factors and are characterized by less secretion of gastric acid. Type II ulcers are due to impaired negative feedback effects of acidification and are characterized by excess secretion of gastric acid (Andrade et al., 1988). Ulcers are also classified into gastric ulcer, duodenal ulcer, esophageal, and meckel's diverticulum ulcer (Goroll and Mulley, 2009) depending on the site of occurrence in the gastro-intestinal tract.

Peptic ulcer disease (PUD) is caused by a lack of equilibrium between the luminal aggressive factors and the mucosal protective factors (Muralidharan and Srikanth, 2009). The predominant causes of peptic ulcer are H. Pylori infection and the therapeutical use of nonsteroidal anti-inflammatory drugs (NSAIDs) such as aspirin (Goroll and Mulley, 2009; Zhang et al., 2014; Feldman et al., 2016). Ulcers and their complications can also be caused by excessive alcohol consumption, smoking, diets (spicy food), emotional and psychosocial stress, genetic factors, ingestion of poisonous and other harmful substances and certain diseases (Andrade et al., 1988; Devi et al., 2011; Feldman et al., 2016).

Hannoa klaineana (Family: Simaroubaceae; genus: Hannoa) is traditionally used in many African countries in the treatment of many diseases such as cancer, malaria and fevers and various gastro-intestinal diseases including peptic ulcer (Basilevskai and Bouquet, 1969). In Nigeria, the plant is locally called "Takardar giwa" (in Hausa) and "Ofor" (in Igbo) and has been used in the North West, North East, and South East parts of the country for the treatment of various ailments including ulcer (François et al., 1998). Studies showed that the plant exhibited activities against $P$. fulciulcerrum in vitro and in vivo, and against a number of cancer cell lines (Monjour et al., 1987; Ang et al., 1995). The plant has been reported to possess antioxidant and antimicrobial activities as evidenced by its free-radical scavenging potential and significant LDH inhibitory effect (Odeghe et al., 2006).

Conventional treatment of peptic ulcer disease (PUD) is associated with several challenges including high relapse rates and many side effects such as arrhythmias, gynaecomastia, hypergastrinaemia, nausea, dizziness, diarrhea, and constipation (Akah et al., 2007; Ahmad 
et al., 2013; BNF, 2018). Many studies confirmed the effectiveness of medicinal plants in the treatment of peptic ulcer diseases (PUDs) and their complications (Nwafor and Okoye, 2005; Akah et al., 2007; Jhasnsi et al., 2010). Previous studies by the Authors showed that crude methanol extract and its solvent fractions of the leaves of Hannoa klaineana exhibited strong anti-ulcer activity and ethylacetate fraction was the most active fraction. This study aims at evaluating the gastro-protective effect of the ethylacetate fraction of the leaves of Hannoa klaineana (Simaroubaceae) and to elucidate its mechanism of action in different ulcer models.

\section{Materials and methods}

\subsection{Experimental animals}

A total of 60 Wistar rats weighing 180-200g were purchased from the Animal House Unit of Usmanu Danfodiyo University, Sokoto. The animals were housed in polycarbonate cages containing pine wood chip beddings; five rats per cage. They were acclimatized to the standard vivarium conditions (temperature $23 \pm 2^{\circ} \mathrm{C}$, relative humidity $30-70 \%$, and 14 hours light -10 hours dark cycle) for one week before the commencement of the experiment. They were fed with commercial rat's pellets and water provided ad libitum.

\subsection{Collection and identification of the plant sample}

The fresh leaves of Hannoa klaineana were collected from Anka forest and Shinkafi town in Zamfara state with the help of traditional herbalists in Sokoto Old Market. The plant was identified and authenticated (UDUH/ANS/0335) at the Herbarium Unit, Department of Biological Sciences, Usmanu Danfodiyo University, Sokoto.

\subsection{Preparation of the plant extract}

Fresh leaves of the Hannoa klaineana were dried in a clean ventilated room for one week. The dried leaves were weighted and grounded to fine powder using pestle and mortar. One thousand gram $(1000 \mathrm{~g})$ of the dried powdered leaves was soaked in $2.5 \mathrm{~L}$ of methanol for 72 hours with intermittent stirring. The extract was filtered through Whatman filter paper, and the filtrate was concentrated in rotary evaporator at $40^{\circ} \mathrm{C}$ under reduced pressure for 3 hours. The final residue was weighed and percentage yield was calculated and then stored at $4^{\circ} \mathrm{C}$ before use.

\subsection{Fractionation}

The crude methanol leaves extract of the Hannoa klaineana was fractionated by liquid-liquid fractionation in a separation funnel. The dried extract $(20 \mathrm{~g})$ was suspended in distilled water, and then fractionated with ethylacetate. The partitioning was performed three times by mixing $300 \mathrm{~mL}$ of ethylacetate with the aqueous phase, shaked vigorously and kept for $10 \mathrm{~min}$ to settle between the layers. The aqueous residue settled down and ethylacetate portion was collected and then labelled as ethylacetate fraction. The fraction was concentrated in rotary evaporator under reduced pressure. The solid fraction obtained was weighed and the percentage yield of the fraction was calculated.

\subsection{Anti-ulcer activity}

\subsubsection{Aspirin-induced ulcer model}

In aspirin-induced gastric ulcer model, the study was conducted according to the method described by Esplugues et al. (1982) with some modifications. Wistar rats $(\mathrm{n}=30)$ weighing $180-200 \mathrm{~g}$ were randomly divided into six groups of 5 rats each. Group 1 received normal saline $(10 \mathrm{ml} / \mathrm{kg}$ bw./day) and served as normalcontrol group. Group 2 was treated as negative control group in which no pre-treatments were given. Group 3 received reference standard drug, omeprazole (20mg/kg bw./day) (MFDS, 2014) and served as positive control group. Group 4, 5 and 6 were pre-treated with 50,100 and $200 \mathrm{mg} / \mathrm{kg}$ bw doses of the fraction, respectively. The animals in the respective groups were pre-treated with the solvent fraction and the standard drug for 3 days. After the treatment, the animals were fasted for 24 hours but allowed free access to water. On the $4^{\text {th }}$ day, thirty minutes after the final treatment, gastric ulcer was induced in rats by administration of aspirin (200 mg/kg, p.o.) (Datta et al. 2002). After 4 hours the animals were anaesthetized and then sacrificed by cervical dislocation.

\subsubsection{Histamine-induced ulcer model}

Histamine-induced gastric ulcer model was performed according to the method described by Shan et al. (2006) and Malairajan et al. (2007). Wistar rats $(n=30)$ weighing $180-200 \mathrm{~g}$ were randomly divided into six groups of 5 rats each. Group 1 received normal saline $(10 \mathrm{ml} / \mathrm{kg}$ bw./day) and served as normalcontrol group. Group 2 was treated as negative control group in which no pre-treatments were given. Group 3 received reference standard drug, famotidine $(20 \mathrm{mg} / \mathrm{kg}$ bw. p.o.) (Bharti et al., 2010) and served as positive control group. Group 4, 5 and 6 were pre-treated with 50,100 and $200 \mathrm{mg} / \mathrm{kg}$ bw doses of the fraction, respectively. The animals in the respective groups were pre-treated with the solvent fraction and the standard drug for 3 days. After the treatment, the animals were fasted for 24 hours but allowed free access to water. On the $4^{\text {th }}$ day, thirty minutes after the final treatment, gastric ulcer was induced in rats by administration of histamine acid phosphate (100 mg/kg i.p.) (Maity et al., 1995). Animals were sacrificed after 4 hours of the ulcer induction by cervical dislocation.

\subsection{Isolation of stomachs and collection of gastric juice}

The carcass stomachs were removed after midline incision in the abdomen of the rats, and then fixed in $10 \%$ neutral buffered formalin prior to examination of ulcer. The entire gastric content was drained into centrifuge tubes through a small nick along the greater curvature and the gastric volume was read directly from the graduation on the centrifuge tubes. 


\subsection{Gross and microscopic examination of ulcers}

The carcass stomachs were dissected opened along the greater curvature and rinsed with distilled water to remove gastric contents and blood clots. The stomachs were mount on a glass slide and observed for detection of gastric lesions using 10× magnification lens and dissecting microscope and then the number and the length of gastric lesions were evaluated (Sánchez et al., 2010).

\subsection{Scoring of ulcers}

Ulcers were scored based on their severity according to a method adopted by Kulkarni (2002) as follows:

$0=$ Normal appearance of stomach

$0.5=$ Red appearance of stomach

$1=$ Spot ulcer

$1.5=$ Hemorrhagic streaks

$2=$ Ulcer $\geq 3 \mathrm{~mm}^{2}$ but $\leq 5 \mathrm{~mm}^{2}$

$3=$ Ulcer $>5 \mathrm{~mm}^{2}$

\subsection{Calculation of ulcer index and percentage gastro-protection}

Ulcer index was calculated using the formula below:

$\mathrm{UI}=\mathrm{UN}+\mathrm{US}+\mathrm{UP} \times 10^{-1}($ Jyoti et al., 2012)

Where; UI = Ulcer Index; UN = Average of number of ulcer per animal; US = Average of severity score; UP = Percentage of animals with ulcer

The percentage gastro-protection was calculated using the formula below:

$\%$ gastro protection $=\frac{\text { UIC-UIT }}{\text { UIC }} \times 100$ (Jyoti et al., 2012)

Where; UIC = Ulcer Index of Control; UIT = Ulcer Index of Test

\subsection{Evaluation of $\mathrm{pH}$}

Five mile $(5 \mathrm{~mL})$ of distilled water was added into the centrifuge tubes containing the gastric juice and centrifuged at $10000 \mathrm{rpm}$ for 5 minutes. The clear supernatant was separated and the $\mathrm{pH}$ of gastric acid was measured using $\mathrm{pH}$ meter (Nwinyl and Kwanashie, 2013).

\subsection{Determination of free and total acidity}

One mile $(1 \mathrm{~mL})$ of the gastric juice was pipetted out in $100 \mathrm{~mL}$ conical flask and two-three drops of topfer's reagent (Dimethyl-aminoazo-benzene with phenolphthalein) was added into the conical flask. The solution was titrated with $0.01 \mathrm{~N} \mathrm{NaOH}$ until all traces of pink colour disappears and the colour of the solution turns to yellowish orange, then the volume of alkali added was recorded. This volume corresponds to free acidity. Titration was continued until pink color of solution reappears. Again the total volume of alkali added was recorded. This volume corresponds to total acidity. Acidity $(\mathrm{mEq} / 1 \mathrm{~L} / 100 \mathrm{gm})$ was calculated using the formula below:

Free/Total acidity $(\mathrm{mEq} / \mathrm{L} / 100 \mathrm{gm})=\frac{\text { VolumsofN } \mathrm{OH} \mathrm{H} \text { Nomality } 100}{0.1}($ Shay et al., 1954)

\section{Results}

\subsection{Aspirin-induced gastric ulcer model}

Fig.1 shows the gross appearance of the stomachs of rats in aspirin-induced ulcer model. Administration of aspirin caused severe lesions with extensive haemorrhages in the gastric mucosa of the negative control rats (Fig.1B). Pre-treatment of the rats with the ethylacetate fraction reduced the damage in a dose dependent manner. The gastric mucosa of the rats pre-treated with $50 \mathrm{mg} / \mathrm{kg}$ dose of the solvent fraction showed spot ulcer (Fig.1D). The rats pre-treated with 100 and $200 \mathrm{mg} / \mathrm{kg}$ doses of the solvent fraction and the omeprazole (20 $\mathrm{mg} / \mathrm{kg}$ ) showed normal appearance of the mucosa (Fig.4E, F and C, respectively).
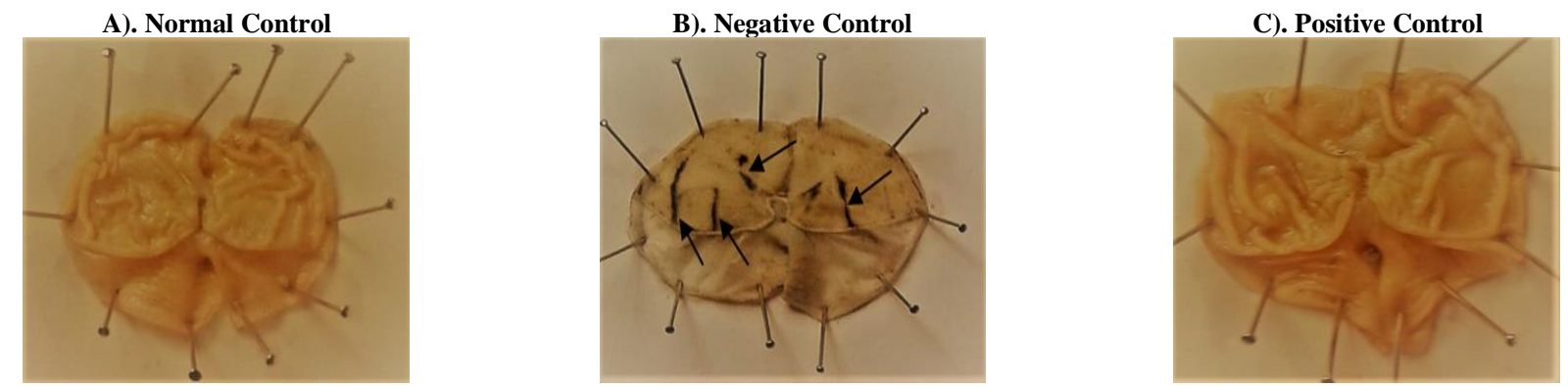


\section{D). EtyAc (50 mg/kg)}

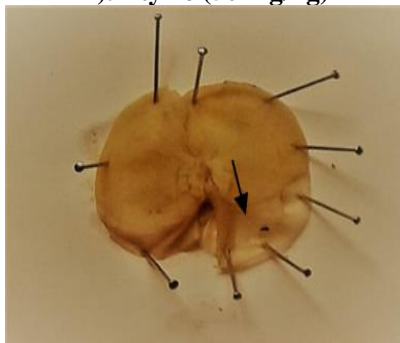

E). EtyAc (100 mg/kg)

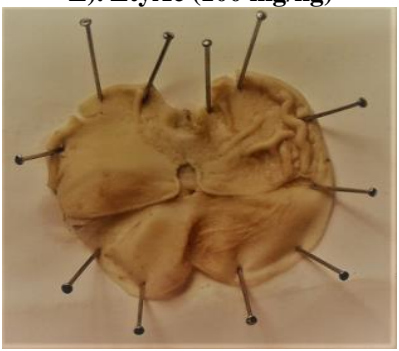

F). EtyAc (200 mg/kg)

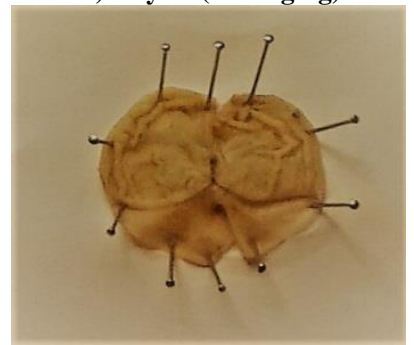

Fig. 1: Gross Appearance of the Stomach of Rats in Aspirin-Induced Gastric Ulcer Model. Normal Appearance of the Mucosa (A: 10ml/kg Normal saline), Severe Lesions (B: 200mg/kg Aspirin), Normal Appearance of the Mucosa (C: 20mg/kg Omeprazole), Spot Ulcer (D), Normal Appearance of the Mucosa (E), Normal Appearance of the Mucosa (F), Ethylacetate (EtyAc), Damage (Arrow).

The effect of ethylacetate fraction of the Hannoa klaineana on the aspirin-induced gastric mucosal damage is shown in Fig.2. The result showed a significant $(p<0.05, p<0.01, p<0.001)$ decreased in mean ulcer index in the pre-treated rats with 50,150 and $200 \mathrm{mg} / \mathrm{kg}$ doses of the solvent fraction and the omeprazole ( $20 \mathrm{mg} / \mathrm{kg}$ ), the standard drug as compared to the negative control rats (Fig.2).

Fig.3 shows the percentage gastroprotection of ethylacetate fraction of the Hannoa klaineana against the aspirin-induced gastric lesions. The solvent fraction exhibited protective effect in a dose dependent manner. The maximum protective effect (99.84\%) against the gastric damages was found at $200 \mathrm{mg} / \mathrm{kg}$ dose of the solvent fraction and is more than that demonstrated by the reference standard drug, omeprazole (64.36\%) (Fig.3).

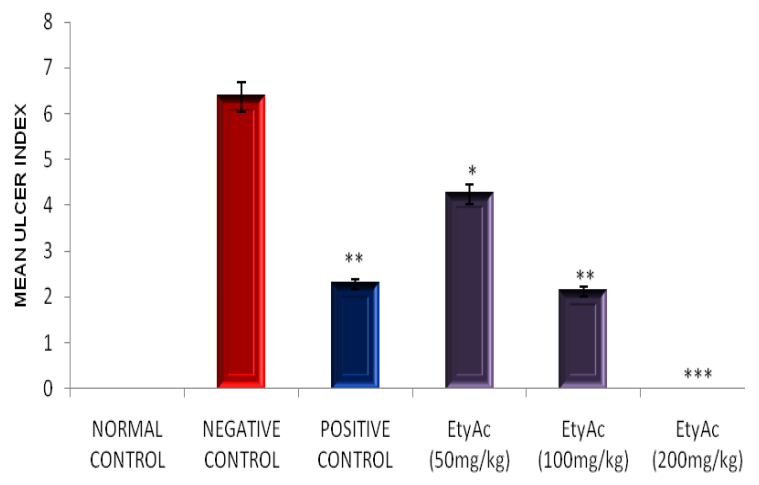

TREATMENT GROUP

Fig. 2: Effect of Ethylacetate Fraction of the Hannoa Klaineana on Aspirin-Induced Gastric Ulcer Model.

$* p<0.05, * * p<0.01, * * * p<0.001$ statistically significant when compared with negative control (One-way ANOVA) followed by Tukey's multiple comparison test. Normal control (10 ml/kg, Normal saline), Negative control (200mg/kg Aspirin), Positive control (20mg/kg, Omeprazole), ethylacetate (EtyAc).

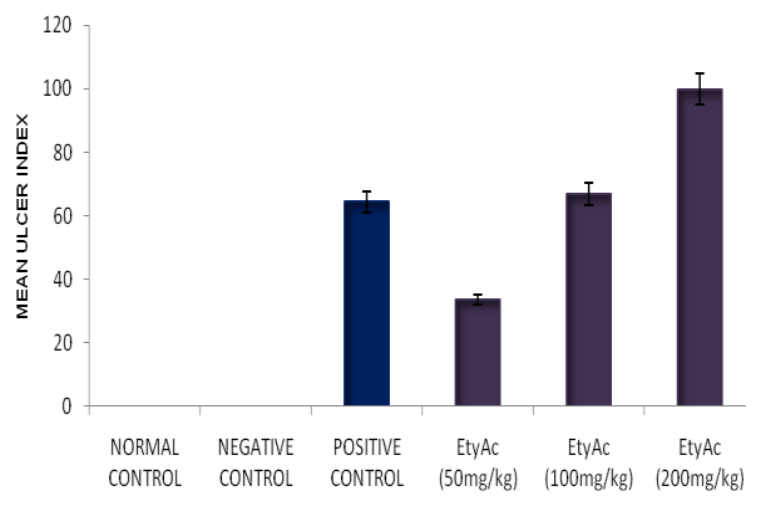

TREATMENT GROUP

Fig. 3: Percentage Gastroprotection of Ethylacetate Fraction of the Hannoa Klaineana in Aspirin-Induced Gastric Ulcer. Normal Control (10ml/kg, Normal saline), Negative Control (200mg/kg Aspirin), Positive Control (20mg/kg, Omeprazole), Ethylacetate (EtyAc).

The effect of ethylacetate fraction of the Hannoa klaineana on $\mathrm{pH}$, gastric volume, free acidity and total acidity in aspirin-induced ulcer is shown in Table 1.The result showed a significant $(p<0.001)$ increased in $\mathrm{pH}$ of gastric juice coupled with significant $(p<0.001)$ decreased in volume of gastric juice, free and total acidity in the pre-treated rats with all the three doses of the solvent fraction and the standard drug as compared to the negative control group (Table 1).

Table 1: Effects of Ethylacetate Fraction of the Hannoa Klaineana on pH, Gastric Volume, Free and Total Acidity

\begin{tabular}{llll}
\hline Treatment Group & Gastric $\mathrm{pH}$ & Gastric Volume $(\mathrm{mL})$ & Free Acidity $(\mathrm{mEq} / \mathrm{L})$ \\
\hline NORMAL CONTROL & $5.80 \pm 0.35$ & $2.50 \pm 0.13$ & $35.60 \pm 0.50$ \\
NEGATIVE CONTROL & $3.62 \pm 0.37$ & $4.52 \pm 0.21$ & $78.80 \pm 1.15$ \\
\hline
\end{tabular}




\begin{tabular}{|c|c|c|c|c|}
\hline POSITIVE CONTROL & $5.08 \pm 0.29 * * *$ & $2.66 \pm 0.18 * * *$ & $19.20 \pm 1.68 * * *$ & $49.00 \pm 1.14 * * *$ \\
\hline EtyAc $(50 \mathrm{mg} / \mathrm{kg})$ & $5.34 \pm 0.23 * * *$ & $2.54 \pm 0.19 * * *$ & $20.00 \pm 1.00 * * *$ & $50.00 \pm 1.84 * * *$ \\
\hline EtyAc $(100 \mathrm{mg} / \mathrm{kg})$ & $6.34 \pm 0.19 * * *$ & $2.34 \pm 0.20 * * *$ & $3.05 \pm 1.36 * * *$ & $21.00 \pm 1.44 * * *$ \\
\hline EtyAc $(200 \mathrm{mg} / \mathrm{kg})$ & $7.42 \pm 0.23 * * *$ & $1.54 \pm 0.17 * * *$ & $2.60 \pm 0.81 * * *$ & $2.55 \pm 1.40 * * *$ \\
\hline
\end{tabular}

Values are mean \pm SEM ( $=5$ rats/group).

*** $p<0.001$ statistically significant when compared with negative control (One-way ANOVA) followed by Tukey's multiple comparison test. Normal control (10ml/kg, Normal saline), Negative control (200mg/kg Aspirin), Positive control (20mg/kg, Omeprazole), ethylacetate (EtyAc).

\subsection{Histamine-induced gastric ulcer model}

Fig. 4 shows the gross appearance of the stomachs of rats in histamine-induced ulcer model. The gastric mucosa of the negative control rats showed prominent ulcers after administration of histamine (Fig.4B). The rats pre-treated with $50 \mathrm{mg} / \mathrm{kg}$ dose of the solvent fraction showed red appearance of the gastric mucosa (Fig.4D). The gastric mucosa of the rats pre-treated with $100 \mathrm{and} 200 \mathrm{mg} / \mathrm{kg}$ doses of the solvent fraction and the standard drug, famotidine showed normal appearance of the gastric mucosa (Fig.4E, F and C, respectively).

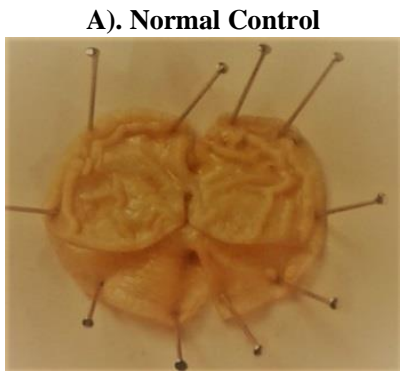

D). EtyAc $(50 \mathrm{mg} / \mathrm{kg})$

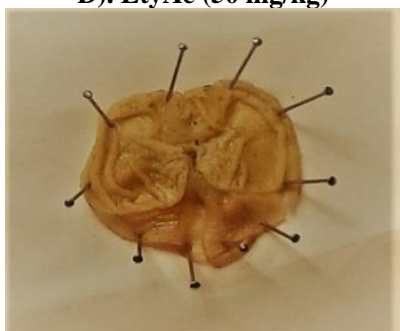

B). Negative Control

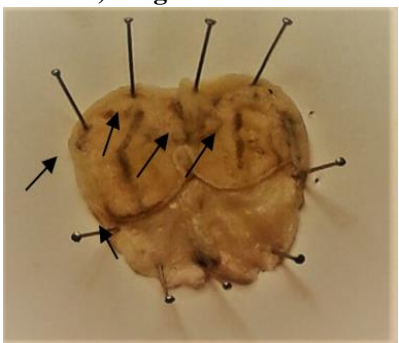

E). EtyAc (100 mg/kg)

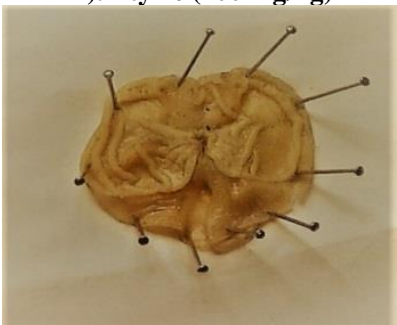

C). Positive Control

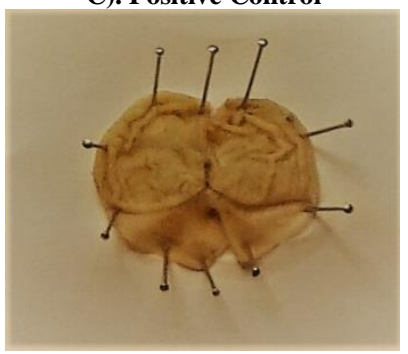

F). EtyAc (200 mg/kg)

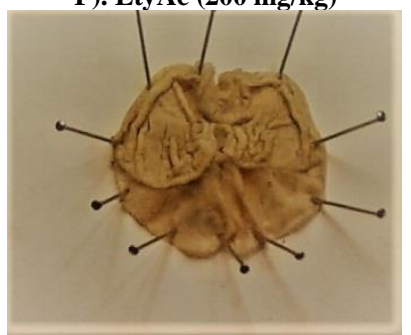

Fig. 4: Gross Appearance of the Stomachs of Rats in Histamine-Induced Gastric Ulcer Model. Normal Appearance of the Mucosa (A: 10ml/kg, Normal saline), Prominent Ulcers (B: $100 \mathrm{mg} / \mathrm{kg}$, i.p. Histamine), Normal Appearance of the Mucosa (C: 20mg/kg Famotidine), Red Appearance of the Mucosa (D), Normal Appearance of the Mucosa (E), Normal Appearance of the Mucosa (F), Ethylacetate (EtyAc), Damage (Arrow).

The effect of ethylacetate fraction of the Hannoa klaineana on histamine-induced gastric ulcer is shown in Fig.5. Pre-treatment of the rats with 50,150 and $200 \mathrm{mg} / \mathrm{kg}$ doses of the solvent fraction and the famotidine $(20 \mathrm{mg} / \mathrm{kg})$ showed a significant $(p<0.001)$ decreased in mean ulcer index in comparison to the negative control group (Fig.5).

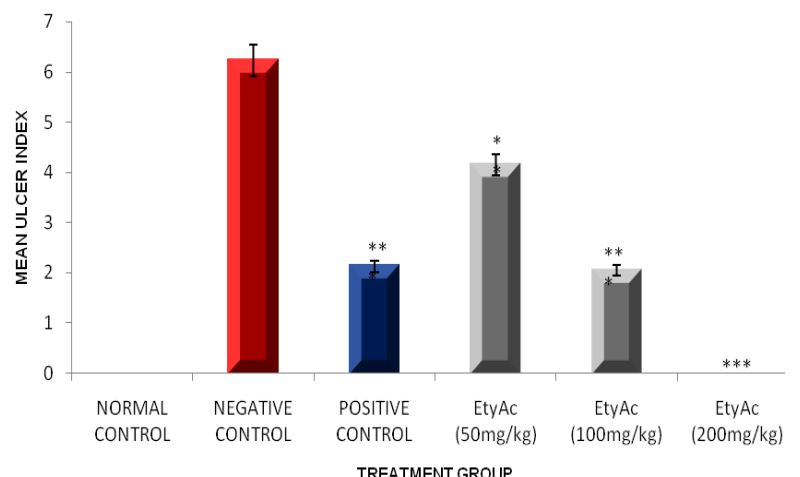

Fig. 5: Effect of Ethylacetate Fraction of the Hannoa Klaineana on Histamine-Induced Gastric Ulcer

$*_{p}<0.05, * * p<0.01, * * * p<0.001$, statistically significant when compared with negative control (One-way ANOVA) followed by Tukey's multiple comparison test. Normal control (10ml/kg, Normal saline), Negative control (100mg/kg, Histamine), Positive control (20mg/kg, Famotidine), ethylacetate (EtyAc).

The percentage gastroprotective effect of ethylacetate fraction of the Hannoa klaineana against the gastric lesion in histamine-induced ulcer model is shown in Fig.6. The solvent fraction exhibited highest protective effect $(99.83 \%)$ against the gastric lesions at $200 \mathrm{mg} / \mathrm{kg}$ and was more than that demonstrated by the famotidine (65.91\%), the reference standard drug (Fig.6). 


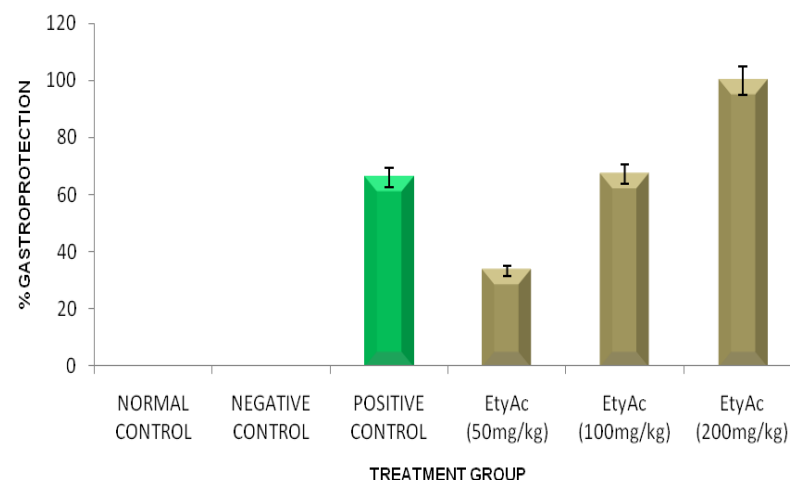

Fig. 6: Percentage Gastroprotection of Ethylacetate Fraction of the Hannoa Klaineana in Histamine-Induced Gastric Ulcer. Normal Control (10m1/kg, Normal saline), Negative Control (100mg/kg, Histamine), Positive Control (20mg/kg, Famotidine), Ethylacetate (Etyac).

Table 2 shows the effect of ethylacetate fraction of the Hannoa klaineana on $\mathrm{pH}$, gastric volume, free and total acidity in histamineinduced gastric ulcer. The result showed a significant $(p<0.001)$ increased in the $\mathrm{pH}$ of gastric juice along with significant $(p<0.001)$ decreased in volume of gastric juice, free and total acidity in the rats pre-treated with 50,100 and $200 \mathrm{mg} / \mathrm{kg}$ doses of the solvent fraction and the standard drug as compared to the negative control group (Table 2).

Table 2:Effects of Ethylacetate Fraction of the Hannoa Klaineana on pH, Gastric Volume, Free and Total Acidity

\begin{tabular}{|c|c|c|c|c|}
\hline Treatment Group & Gastric $\mathrm{pH}$ & Gastric Volume (mL) & Free Acidity $(\mathrm{mEq} / \mathrm{L})$ & Total Acidity $(\mathrm{mEq} / \mathrm{L})$ \\
\hline NORMAL CONTROL & $5.80 \pm 0.35$ & $2.50 \pm 0.13$ & $35.60 \pm 0.50$ & $102.60 \pm 0.50$ \\
\hline NEGATIVE CONTROL & $1.84 \pm 0.15$ & $6.38 \pm 0.35$ & $109.60 \pm 3.99$ & $252.00 \pm 2.75$ \\
\hline POSITIVE CONTROL & $4.00 \pm 0.25 * * *$ & $3.64 \pm 0.14 * * *$ & $46.60 \pm 2.04 * * *$ & $101.00 \pm 2.64 * * *$ \\
\hline EtyAc $(50 \mathrm{mg} / \mathrm{kg})$ & $3.98 \pm 0.21 * * *$ & $4.02 \pm 0.13 * * *$ & $48.80 \pm 2.55 * * *$ & $107.80 \pm 2.81 * * *$ \\
\hline EtyAc $(100 \mathrm{mg} / \mathrm{kg})$ & $5.28 \pm 0.22 * * *$ & $2.68 \pm 0.11 * * *$ & $18.60 \pm 1.20 * * *$ & $45.40 \pm 2.01 * * *$ \\
\hline EtyAc $(200 \mathrm{mg} / \mathrm{kg})$ & $7.04 \pm 0.20 * * *$ & $1.18 \pm 0.08 * * *$ & $8.60 \pm 1.43 * * *$ & $17.00 \pm 1.64 * * *$ \\
\hline
\end{tabular}

Values are mean \pm SEM $(\mathrm{n}=5$ rats/group).

$* * * p<0.001$ statistically significant when compared with negative control (One-way ANOVA) followed by Tukey's multiple comparison test. Normal control (10ml/kg, Normal saline), Negative control (100mg/kg, Histamine), Positive control (20mg/kg, Famotidine), ethylacetate (EtyAc).

\section{Discussion}

\subsection{Effect of ethylacetate fraction of the Hannoa klaineana on aspirin-induced gastric ulcer in rats}

Non-steroidal anti-inflammatory drugs (NSAIDs) such as aspirin induce mucosal injury by several mechanisms. The biochemical actions common to all conventional NSAIDs are inhibition of prostaglandin synthesis, decreased mucus and bicarbonate secretion, and topical irritation of the gastric epithelium (Whittle, 1977; Whittle, 1992; Wallace, 2008). Non-steroidal anti-inflammatory drugs (NSAIDs) disrupt mucus phospholipids of the gastric mucosa leading to uncoupling of mitochondrial oxidative phosphorylation thereby resulting to mucosal damage (Glarborg et al., 1976; Spenny and Bhown, 1977; Bhala et al., 2013).

Non-steroidal anti-inflammatory drugs (NSAIDs) inhibit activity of cycloxygenase enzyme (COX-1 and COX-2) the rate-limiting enzyme in the conversion of arachidonic acid to prostaglandins (Del et al., 2003). Prostaglandins play a vital protective role via enhancing the mucosa's resistance to injury under certain conditions, perhaps by increasing mucosal blood flow (Robert, 1979; Gaskill et al., 1982), stimulating the secretion of mucus and bicarbonate (Hogan et al., 1994), strengthening of the gastric mucosal barrier (Takeuchi and Nobuhara, 1981), increasing release of endogenous mediators of gastric cytoprotection (Szabo et al., 1981) and regulating mucosal cell turnover and repair (Hawkey and Ramton, 1985).

Aspirin is known to be potent inhibitor of prostaglandin (PG) biosynthesis (Whittle, 2003) characterized by gastric damage and hemorrhage (Toruner, 2007). The drug is frequently used as a model in studies on in vivo cytoprotective effect of a chemical substance (Rajkapoor et al., 2002). In this study, pre-treatment of the rats with ethylacetate fraction of the Hannoa klaineana significantly decreased mean ulcer index with the maximum protective effect $(99.84 \%)$ at $200 \mathrm{mg} / \mathrm{kg}$ against the gastric damages.

Hydrolytic $(\mathrm{HCl})$ and proteolytic (pepsin) activities in stomach are important determinants of development of gastric ulcer (Lüllmann et al., 2000). Secretion of gastric (hydrochloric) acid and pepsin is responsible for the potential of causing mucosal damage (Das et al., 1997). The result in this study showed a significant $(p<0.001)$ increased in $\mathrm{pH}$ of gastric juice coupled with significant $(p<0.001)$ decrease in gastric volume, free and total acidity in rats pre-treated with varying doses of the ethylacetate fraction. Changes in $\mathrm{pH}$ value are associated with pathogenesis of ulcer and gastric damage in experimental animals (Lüllmann et al., 2000). High pH value is associated with decrease in hydrogen ion $\left(\mathrm{H}^{+}\right)$concentration in gastric juice. Decrease in gastric acidity is an important improvement in the treatment of peptic ulcer disease (Proctor and Deans, 2014).

\subsection{Effect of ethylacetate fraction of Hannoa klaineana on histamine-induced gastric ulcer in rats}

The induction of gastric ulcers by histamine administration has long been recognized (Amagase and Okabe, 2003). The basis of the histamine induced gastric ulcer model is mediating formation of gastric ulcers by the release of histamine (Adinortey et al., 2013). Histamine released from mast cells binds with receptors present on the surface of parietal cells and causes activation of adenylate cyclase which converts ATP into c-AMP subsequently enhanced secretion of gastric acid (Sander et al., 2006). The model is use to evaluate antisecretory effects of a chemical agent against ulcers and agents that function as H2-receptor antagonists (Hay et al., 1942). In this study, pre-treatment of the rats with ethylacetate fraction significantly $(p<0.001)$ decreased mean ulcer index with the protective effect up to 99.83\% against the histamine-induced gastric lesions. 
Histamine (2-[4-emidazolyl] ethylamine) is a biogenic molecule synthesized by L-histidine decarboxylase (HDC) from the amino acid histidine (Moody and Davis, 1970). Histamine released from gastric mucosa can affect mucosal blood vessels and change their permeability (O'Brien and Silen, 1973). Fiocca et al. (1974) and Moody and Davis, 1970) have shown that administration of histamine increased the ionic permeability of the gastric mucosal barrier. In the present study, pre-treatment of the rats with $50,100 \mathrm{and} 200 \mathrm{mg} / \mathrm{kg}$ doses of the ethylacetate fraction showed a significant increased $(p<0.001)$ in $\mathrm{pH}$ of gastric juice along with significant $(p<0.001)$ decreased in gastric volume, free and total acidity. High $\mathrm{pH}$ value is associated with decreased in hydrogen ions concentration in the gastric juice (Lullmann et al., 2000).

\section{Conclusion and recommendation}

The mechanism of gastroprotective effect of ethylacetate fraction of the Hannoa klaineana in aspirin-induced gastric ulcer model could be attributed to its ability to stimulate prostaglandins secretion or possess prostaglandins like-substances. Also, the protective effect of the solvent fraction against the histamine-induced gastric ulcer could be attributed to the suppression of histamine-induced vasospastic effect and gastric secretion. Further study could be done to characterize the specific compounds responsible for the gastroprotective effect of ethylacetate fraction of the Hannoa klaineana.

\section{References}

[1] Adinortey, M. B., Ansah, C., Galyuon, I. and Kwadwo, N. A. (2013). In vivo Models used for Evaluation of Potential Anti-gastroduodenal Ulcer Agents. Hindawi Publishing Corporation. p. 1-12.https://doi.org/10.1155/2013/796405.

[2] Ahmad, A., Santosh, V. K. and Maurya, K. (2013). Natural Anti-ulcer Agents: A Pharmacological Review. Inter. J. Res. Pharmaceut. Biomed. Sci. 4(2):535-541.

[3] Akah, P. A., Nnaeto, O., Nworu, C. S. and Ezike, A. C. (2007). Medicinal Plants Used in the Traditional Treatment of Peptic Ulcer Diseases: A Case Study of Napoleona vogelii Hook and Planch (Lecythidaceae). Res. J. Pharmacol. 1(3): 67-74.

[4] Almeida, L. L. A., Rolim, L. A., Santos, V. L. and Wanderley, A. G. (2017). Spondias purpurea L. (Anacardiaceae): Antioxidant and Antiulcer Activities of the Leaf Hexane Extract. Oxid. Med. Cell. Longev., p 1-14.https://doi.org/10.1155/2017/6593073.

[5] Amagase, K. and Okabe, S. (2003). On the Mechanisms Underlying Histamine Induction of Gastric Mucosal Lesions in Rat with Partial Gastric Vascular Occlusion. J. Pharmacol. Sci. 92: 124-136.https://doi.org/10.1254/jphs.92.124.

[6] Andrade-Neto, V. F., Pohlit, A. M., Pinto, A. C., Silva, E. C., Nogueira, K. L., Melo, M. R., Henrique, M. C., Amorim, R. C., Silva, L. F., Costa, M. R., Nunomura, R. C., Nunomura, S. M., Alecrim, W. D., Alecrim, M. D., Chaves, F. C. and Vieira, P. F. (2007). In vitro Inhibition of Plasmodium Falciparum by Substances Isolatade from Amazonian Antimalarial Plants. Mem. I. Oswaldo Cruz 102: 359365.https://doi.org/10.1590/S0074-02762007000300016.

[7] Ang, H. H., Chan, K. L. and Mak, J. W. (1995). In vitro Antimalarial Activity of Quassinoids from Eurycomalongifolia against Malaysian Chloroquine-Resistant Plasmodium Falciparum Isolates. PO1 Planta Med. 61: 177-178.https://doi.org/10.1055/s-2006-958042.

[8] Basilevskaia, V. (1969). Pluntes Mbdicinales de Guine'e. Conakry, Republique de Guinee, p. 126.

[9] Bhala, N., Emberson, J. and Merhi, A. (2013). Vascular and Upper Gastrointestinal Effects of Non-Steroidal Anti-Inflammatory Drugs: MetaAnalyses of Individual Participant Data from Randomised Trials. Lancet. 382 (98):769-779. https://doi.org/10.1016/S0140-6736(13)60900-9.

[10] Bharti, S., Wahane, V. D. and Kumar, V. L. (2010). Protective Effect of Calotropisprocera latex Extracts on Experimentally Induced Gastric Ulcers in Rat. J. Ethnopharmacol. 127: 440-444.https://doi.org/10.1016/j.jep.2009.10.016.

[11] British National Formulary(BNF) (2018). 76 (76 ed.). Pharmaceutical Press. p. 73.

[12] Das, D., Bandyopadhyay, D., Bhattacharjee, M. and Banerjee, R. K. (1997). Hydroxyl Radical is the Major Causative Factor in Stress-Induced Gastric Ulceration. Free Radical Biology and Medicine. 23(1): 8-18.https://doi.org/10.1016/S0891-5849(96)00547-3.

[13] Datta, G. K., Sairam, K., Priyambada, S., Debnath, P. K. and Goel, R. K. (2002). Antiulcerogenic Activity of Satavarimandw: An Ayurvedicherbo Medical Preparation. Indian J. Exp. Biol. 40: 1173-1177.

[14] Del, B. T., Borgoni, R., Del, B. P., Edaro, P., Vianello, F. and Danieli, G. A. (2003). Peptic Ulcer Inheritance in Patients with Elevated Serum Pepsinogen Group Levels and without Infection of Helicobacter pylori. Dig. Liver Dis. 32: 12.https://doi.org/10.1016/S1590-8658(00)80038-9.

[15] Devi, K. N., Raja, N. R. L., Palanivelu, M., Srinivasan, B., Rajarathinam, D., Kiran, C. K. and Niranjan, P. (2011). Anti-ulcer activity of the Leaves of Punica granatum Linn. Asian J. Biochem. Pharmaceut. Res. 4(1):116-122.

[16] Esplugues, J., Lloris, J. M., Marti-Bonmati, E. and Morcillo, E. J. (1982). Effects of Adrenoceptor Drug Stimulation on Various Models of Gastric Ulcer in Rats. Br. J. Pharmacol. 76: 587-94.https://doi.org/10.1111/j.1476-5381.1982.tb09258.x.

[17] Feldman, M., Friedman, L. S. and Brandt, L. J. (2016). Sleisenger and Fordtran's Gastrointestinal and Liver Disease: Pathophysiology/Diagnosis/Management. 10 $0^{\text {th }}$ ed Philadelphia, PA: Saunders/Elsevier. 2: 2369-2389.

[18] Fiocca, F., Basso, N. and Passaro, E. P. (1974). Effect of Histamine on Isolated Human Gastric Mucosa. Surg. Forum 25:321-323.

[19] Gaskill, H. U., Sirinek, K. R. and Levine, B. A. (1982). Effect of Prostacyclin on Mucosal Blood Flow. Surgery 92: 220-225.

[20] Glarborg J. T., Weis-Fogh, U. S. and Neilsen, H. H. (1976). Salicylate- and Aspirin-Induced Uncoupling of Oxidative Phosphorylation in Mitochondria isolated from the Mucosal Membrane of the Stomach. Scand J. Lab. Invest. 36: 649-653.https://doi.org/10.3109/00365517609054490.

[21] Goroll, A. H. and Mulley, A. G. (2009). Primary Care Medicine. Philadelphia, 6: 537- 548.

[22] Hawkey, C. J. and Ramton, D. S. (1985). Prostaglandins and the Gastrointestinal Mucosa. Are They Important in Its Function, Disease or Treatment? Gastroenterology. 89: 1162-1168.https://doi.org/10.1016/0016-5085(85)90225-2.

[23] Hay, L. J., Varco, C. F., Code, O. F. and Wangensteen, R. L. (1942). "Experimental Production of Gastric and Duodenal Ulcers in Laboratory Animals by Intramuscular Injection of Histamine in Bees wax," The Journal of Surgery, Gynecology and Obstetrics. 74: 70-182.

[24] Hogan, D. L., Ainsworth, M. A. and Isenberg, J. I. (1994). Review Article: Gastroduodenal Bicarbonate Secretion. Aliment Pharmacol. Ther. 8(5):475-488. https://doi.org/10.1111/j.1365-2036.1994.tb00319.x.

[25] Jhasnsi, R. M., Mohana, I. S. and Saravana, K. A. (2010). Review on Herbal Drug For Anti-Ulcer Propetrty. International Journal of Biological and Pharmaceutical Research ICID. 20-26.

[26] Jyoti, G., Dinesh, K. and Ankit, G. (2012). Evaluation of Gastric Anti-Ulcer Activity of Methanolic Extract of Cayratiatrifoliain Experimental Animals. Asian Pacific J. Trop. Dis, 1: 99-102.https://doi.org/10.1016/S2222-1808(12)60024-3.

[27] Klein-Junior, L. C., Gandolfi, R. B., Santin, J. R., Lemos, M., Cechinel, F. V. and Andrade, S. F. (2010). Antiulcerogenic Activity of Extract, Fractions, and some Compounds obtained from Polygola cyparissias St Hillaire \& Moquin (Poligalaceae). Naunyn Schmiedebergs Arch. Pharmacol. 381:121-126. https://doi.org/10.1007/s00210-009-0485-x.

[28] Klein-Júnior, L. C., Santin, J. R., Niero, R., deAndrade, S. F. and Cechinel-Filho, V. (2012). The Therapeutic Lead Potential of Metabolites obtained from Natural Sources for the Treatment of Peptic Ulcer. Phytochem. Rev. 11(4): 567-616.https://doi.org/10.1007/s11101-012-9262-4.

[29] Kulkarni, S. K. (2002). Hand Book of Experimental Pharmacology, Vallabh Prakashan, New Delhi, India, $3^{\text {rd }}$ ed. Remedies. Phytother. Res. 14:581-591.

[30] Kumar, A., Dewan, B. and Rama, T. (2011). Evaluation of Anti-ulcerogenic Properties from the root of Flemingia strobilifera. J. Basic Clin. Pharm. 2(1): 33-39. 
[31] Lüllmann, H., Mohr, A., Ziegler, D. and Bieger, K. (2000). Color Atlas of Pharmacology, $2^{\text {nd }}$ ed., Thieme Stuttgart, New York, pp. 166.

[32] Maity, S., Vedasiromoni, J. R. and Ganguly, D. K. (1995). Anti-ulcer Effect of the Hot Water Extract of Black Tea (Camellia sinensis). Journal of Ethnopharmacology. 46: 167 - 174.https://doi.org/10.1016/0378-8741(95)01245-9.

[33] Malairajan, P., Gopalkrishnan, G., Nrasimhan, S., Jessi, K., Veni, K. and Kavimani, S. (2007). Anti-ulcer Activity of Crude Alcoholic Extract of Toonaciliata roemer (heart wood). J. Ethnopharmacol. 110: 348-57.https://doi.org/10.1016/j.jep.2006.10.018.

[34] Ministry of Food Drug Safety (MFDS). Food Code. Korean Foods Industry Association, Seoul, Korea. 2014.

[35] Monjour, L., Rouquier, F., Alfred, C. and Polonsky, J. (1987). Essais De traitement Du paludismemurin Experimental Par un Quassino'ide, Laglaucarubinone. CRAcad Sci. Paris, III. Sciences dela Vie 304: 129-132.

[36] Moody, F. G. and Davis, W. L. (1970). Hydrogen and Sodium Permeation of Canine Gastric Mucosa during Histamine and Sodium Thiocyanate Administration. Gastroenterology 59:350-357.https://doi.org/10.1016/S0016-5085(19)33728-X.

[37] Muralidharan, P. and Srikanth, J. (2009). Antiulcer Activity of Morinda citrifolia Linn fruit Extracts. J. Sci. Res., 1(2): 345352.https://doi.org/10.3329/jsr.v1i2.1625.

[38] Nwafor, S. V. and Okoye, C. F. (2005). Antiulcer Properties of Ethanol Root Extract of Cissampelos Mucronata. Pharm. Biol. 43 (5):396403.https://doi.org/10.1080/13880200590963222.

[39] Nwinyl, F. C. and Kwanashie, S. (2013). Comparative Effects of Sorghum bicolor Leaf Base Extract on Tissues Isolated from Some Body System of Experimental Animals. J. Med Plants Res, 7 (41): 3041-305.

[40] O'Brien, P. and Silen, W. (1973). Effect of Bile Salts and Aspirin on the Gastric Mucosal Blood Flow. Gastroenterology 64:246253.https://doi.org/10.1016/S0016-5085(73)80036-8.

[41] Odeghe, O. B, Monanu, M. O. and Anacletus F. C. (2016). In vitro Antioxidant Abilities and Inhibition of Rabbit Muscle Lactate Dehydrogenase by Aqueous Extract of Hannoa klaineana stem bark. International Journal of Advanced Research 4 (2): $509-515$.

[42] Proctor, M. J. and Deans, C. (2014). Complications of Peptic Ulcers. Surgery (Oxford). 32: 599-607.https://doi.org/10.1016/j.mpsur.2014.09.005.

[43] Rajkapoor, B., Anandan, R. and Jayakar, B. (2002). Anti-ulcer Effect of Nigella saliva Linn Against Gastric Ulcer in Rats. Current Science. 82: $177-179$.

[44] Robert, A., Nezamis, J. E., Lancaster, C. and Hanchar, A. J. (1979). Cytoprotection by Prostaglandins in Hypertonic NaCI and Thermal Injury. Gastroenterology. 77:433-443.https://doi.org/10.1016/0016-5085(79)90002-7.

[45] Sánchez-Mendoza, M. E., Reyes-Trejo, B., Sánchez-Gómez, P., Rodríguez-Silverio, J., Castillo-Henkel, C., Cervantes-Cuevas, H.and Arrieta, J. (2010). Bioassay-Guided Isolation of an Anti-Ulcer Chromene from Eupatorium Aschenbornianum: Role of Nitric Oxide, Prostaglandins and Sulfydryls. Fitoterapia. 81: 66-71.https://doi.org/10.1016/j.fitote.2009.07.009.

[46] Sander, L. E., Lorentz, A., Sellge, G., Coeffer, M., Neipp, M. and Veres, T. (2006). Selective Expression of Histamine Receptors H1R, H2R and H4R, but not H3R, in the Human Intestinal Tract. J. Gut. 55: 498-504. https://doi.org/10.1136/gut.2004.061762.

[47] Shan, L., Liu, R. H., Shen, Y. H., Zhang, W. D., Wu, C. Z. and Min, L. (2006). Gastroprotective Effect of a Traditional Chinese Herbal Drug "Baishouwu" on Experimental Gastric Lesions in Rats. J. Ethnopharmacol. 107: 389-94.https://doi.org/10.1016/j.jep.2006.03.022.

[48] Shay, H., Sun, D. C. H. and Gruenstein, M. (1954). A Quantitative Method for Measuring Spontaneous Gastric Secretion in the Rat. Gastroenterol, 26: 906-913.https://doi.org/10.1016/S0016-5085(54)80008-4.

[49] Spenny, J. G. and Bhown, M. (1977). Effect of Prostaglandin Acid on Gastric Mucosa II. Mucosal ATP and Phosphocreatinine Content and Salicylic Effects on Mitochondrial Meta- bolism. Gastroenterology. 73:995-999. https://doi.org/10.1016/S0016-5085(19)31912-2.

[50] Szabo, S., Trier, J. S. and Frankel, P. W. (1981). Sulfhydryl Compounds May Mediate Gastric Cytoprotection. Science 214:200202.https://doi.org/10.1126/science.7280691.

[51] Takeuchi, K. and Nobuhara, Y. (1981). Inhibition of Gastric Motor Activity of 16,16-dimethyl prostaglandin E: A Possible Explanation of Cytoproteciion. Dig. Dis. Sci. 30:1181-1188. https://doi.org/10.1007/BF01314054.

[52] Toruner, M. (2007). Aspirin and Gastrointestinal Toxicity. Journal of Anatomical Cardiology. 24 (1): 27 - 30.

[53] Wallace, J. L. (2008). Prostaglandins, NSAIDs, and Gastric Mucosal Protection: Why Doesn't The Stomach Digest Itself? Physiol. Rev. 88:15471565.https://doi.org/10.1152/physrev.00004.2008.

[54] Whittle, B. J. (2003). Gastrointestinal Effects of Non-steroidal Anti-inflammatory Drugs. Fundam Clin. Pharmacol. 7:30113.https://doi.org/10.1046/j.1472-8206.2003.00135.x

[55] Whittle, B. J. R. (1977). Mechanism Underlying Gastric Mucosal Damage Induced by Indomethacin and Bile Salt, and the Actions of Prostaglandins. Br. J. Pharmacol. 60: 455-460.https://doi.org/10.1111/j.1476-5381.1977.tb07522.x.

[56] Whittle, B. J. R., Vane, J. R., Botting, R. M. (1992). Unwanted Effects of Aspirin and Related Agents on the Gastrointestinal Tract. Aspirin and other Salicylates. London: Chapman and Hall Medical. 465-509.

[57] Zelickson, M. S., Bronder, C. M., Johnson, B. L., Camunas, J. A., Smith, D. E., Eawlinson, D., Von, S., Stone, H. H. and Taylor, S. M. (2011). Helicobacter pylori is not the Predominant Etiology for Peptic Ulcers Requiring Operation. Am. Surgeon J. 77:1054-1060.

[58] Zhang, L., Ren, J. W., Wong, C. C., Wu, W. K., Ren, S. X., Shen, J., Chan, R. L. and Cho, C. H. (2014). Effects of Cigarette Smoke and Its Active Components on Ulcer Formation and Healing in the Gastrointestinal Mucosa. Curr. Med. Chem. 19: 6369.https://doi.org/10.2174/092986712803413926. 